\section{Nondestructive Measurement of Vegetative Cover Using Digital Image Analysis}

\author{
Mercy A. Olmstead ${ }^{1}$ \\ Department of Horticulture and Landscape Architecture, Washington State \\ University, 24106 N. Bunn Road, Prosser, WA 99350-9687
}

Robert Wample ${ }^{2}$

Department of Viticulture and Enology, 2360 East Barstow Avenue, MS VR89,

Fresno, CA 93740

\section{Stephanie Greene ${ }^{3}$ and Julie Tarara ${ }^{4}$ \\ USDA, ARS National Temperate Forage Legume Germplasm Resources Unit and USDA, ARS Horticultural Crops Research Unit, 24106 N. Bunn Road, Prosser, WA 99350-9687}

Additional index words. cover crops, vineyard management, visual illusions, visual assessment

\begin{abstract}
Traditionally, vegetative cover has been subjectively assessed by visual assessment. However, visual assessment is thought to overestimate percent vegetative cover. Thus, a repeatable method to objectively quantify percent cover is desirable. In two vineyards near Prosser, Wash., the percentage of ground surface covered by up to 15 different cover crops was assessed both visually and by computer-assisted digital image analysis. Quadrats in the cover crop were photographed digitally and the images analyzed with commercially available software. Areas of green vegetation in each image were identified and measured. Weeds in some images were differentiated from the cover crop by userdefined thresholds. Subjective visual estimates of percent vegetative cover were generally higher than those digitally estimated. Values for the visual estimates ranged from $5 \%$ to $70 \%$ in 1998 (mean $=52.4 \%)$ and $7.5 \%$ to $55 \%$ in $1999($ mean $=30.7 \%)$, compared to digital readings ranging from $0.5 \%$ to $24 \%$ (mean $=11.1 \%$ ) and $10.3 \%$ to $36.6 \%$ cover ( mean $=\mathbf{2 0 . 1 \%}$ ), respectively. The visual assessments had lower coefficients of variability in 1998 (Cv 28.1) than the digital image analysis (Cv 52.3), but in 1999, the values for the two techniques were similar (Cv 41.2 vs. Cv 45.7). Despite initial variations between the two methods, the accuracy of digital image analysis for measuring percentage vegetative cover is superior.
\end{abstract}

Soil erosion by wind is a significant concern in vineyards in eastern Washington, in part, because of low rainfall. Both the Columbia and Yakima valleys, where the majority of the state's vineyards are located, lie in the rainshadow of the Cascade Mountains and experience frequent high winds. In some seasons, 2 to $5 \mathrm{~cm}$ of topsoil can be lost by wind erosion. Soil eroded from bare ground accumulates in areas with vegetative cover (Coldwell et al., 1942). Cover crops mitigate

Received for publication 3 Sept. 2002. Accepted for publication $26 \mathrm{Feb}$. 2003. This paper is a portion of a thesis submitted by M.A.O. in partial fulfillment of MS degree requirements at Washington State Univ. We wish to thank the staff and crew of WSU-IAREC, Alderridge Vineyards for use of field plots and equipment, and Corus Brands for their cooperation. We also gratefully acknowledge the northwest Center for Small Fruits Research and the Washington Wine Advisory Board for their financial support.

${ }^{1}$ Former Graduate Student. To whom reprint requests should be sent. Present address: Dept. of Horticulture, Michigan State Univ., East Lansing, MI 48824

1325. E-mail address: neumann6@msu.edu; fax: 517-432-3490.

${ }^{2}$ Director, Viticulture and Enology Research Center. ${ }^{3}$ Plant Geneticist.

${ }^{4}$ Research Horticulturist. the combined effects of low rainfall and high winds by holding soil particles and small aggregates in place, and by reducing runoff (Stredansky, 1999).

To control and reduce soil erosion, percent ground cover, rather than gross biomass, generally is considered the most important factor (Stredansky, 1999). Having as little as $20 \%$ of the soil surface covered with vegetative residue can reduce wind erosion by $40 \%$ to $75 \%$ compared to a clean cultivated field (Freebairn and Wockner, 1986). An accurate method to estimate percent vegetative cover is essential in the evaluation and eventual selection of cover crops for the prevention of soil erosion. Although crop performance and plant communities typically have been described by measurements of stand density and biomass (Dietz and Steinlein, 1996), there are several reasons which favor the use of percent ground covered as the appropriate indicator of cover crop performance. While stand density could be used as an index of percent vegetative cover, density itself does not indicate variability in canopy architecture and lateral spread among mature individuals within a species. Likewise, biomass measurements can be deceptive in estimating percent cover because of differ- ences in layering within the canopy (Dietz and Steinlein, 1996).

Visual estimates are prone to error, often from inadequate training of the assessors (Sherwood et al., 1983) and the limitations of visual perception. Raw perceptual differences between assessors, assessors' experience, and the inherent subjectivity of this method are major sources of errors (Shelton, 1988). Additionally, the Weber-Fechner law (Coren and Girgus, 1978) established visual discrimination increases logarithmically as the intensity of the stimulus (e.g., area of vegetative cover) increases (Lindow and Webb, 1983). Differences detected by the eye are a fixed fraction of the size of the stimulus being increased (Coren and Girgus, 1978). At small amounts of cover, a change in cover is readily noticed; however, at larger amounts of cover, the eye may not detect a change of the same magnitude. Many standard area diagrams that are used in disease ratings are scaled logarithmically to account for this visual limitation (Lindow and Andersen, 1986). Based on the Weber-Fechner law, visual estimates of cover become more accurate when either high or low percentages of cover are assessed (Lindow and Webb, 1983). The human eye directly estimates cover at $\approx 50 \%$ but indirectly assesses cover by estimating noncover areas above $50 \%$ cover. Because the eye can assess accurately only very low or very high amounts of cover, the largest errors in visual assessment occur around 50\% cover (Horsfall and Barratt, 1945; Lindow and Webb, 1983). An objective method of measurement could improve accuracy in the problematic range of visual discrimination.

As an objective indicator of vigor amount of ground covered and overall performance, percent vegetative cover has been measured nondestructively by light interception, using shadows projected on the soil surface by the crop or overhead photographs (Adams and Arkin, 1977). Methods such as line-intercept and wheel-point using transects or grids have been used to quantify vegetative cover in large plots or pasture areas (Molloy and Moran, 1991). Because they are transect based, these methods can have environmental and time limitations, often requiring an entire day depending on plot size. They require full sunlight and must include repeated measurements of different orientations to avoid variations in measurements (Ewing and Horton, 1999). The area of actual ground surface covered by stalks of vegetation has been correlated with percent cover (Stocking, 1988). However, in most cases, vegetative or canopy cover has been subjectively assessed visually.

Use of computer-assisted image analysis eliminates most of the subjective decisions of a human observer (Shelton et al., 1988). Digital image analysis has been used to measure vegetative cover in studies of living mulches and crop residues (Bennett et al., 2000; Beverly, 1996), as well as in forest canopies (Silbernagel and Moeur, 2001). Digital image analysis can also be used to measure the disease incidence on leaves or crops (Lang et al., 2000; Olmstead et al., 2000). The occurrence of the disorder 'blackleaf' in 'Concord' 
grapes (Vitis labrusca L.) was analyzed using remotely sensed images to determine the impact of environmental stress on canopy metabolism (Lang et al., 2000). Leaf shapes have also been identified with image analysis; however in this case, variation in plant maturity compromised accuracy (Woebbecke et al., 1995). Using this technique to detect differences between monocots and dicots resulted in 59\% successful classification of leaf shape relative to standards (Woebbecke et al., 1995). Yonekawa et al. (1996) succeeded in using digital image analysis for detecting shape factors to $\pm 3 \%$ of standard objects with known areas. In another report, digital image analysis was incorporated into a quadrat charting method for plant cover, in which a grid was used as an overlay to aid in the calculation of percent cover (Dietz and Steinlein, 1996). A number of other digital procedures use frames captured from video, but the capture and transfer to a computer can be time consuming and involve expensive equipment. Recently, a study took images of crop cover and analyzed percent cover using individual colors within the images (Gitelson et al., 2002). With recent improvements in technology, digital image analysis methods may become more accurate, less expensive, and less time-consuming than the previously described techniques.

In this study, we describe a digitally-based method for image capture and measurement of percent vegetative cover of cover crops. Our hypothesis was that the objectivity and repeatability of this technique would be superior to subjective visual estimates in analyzing plant cover. This research was part of a larger project to determine and identify specific cover crops suitable for reducing wind erosion within vineyards in the Pacific Northwest.

\section{Materials and Methods}

Experimental design. Plant selections evaluated for their potential as vineyard cover crops were sown at Washington State Univ.'s Irrigated Agriculture Research and Extension Center (WSU-IAREC) in Prosser, Wash. (lat. $46^{\circ} \mathrm{N}$; long. $119.7^{\circ} \mathrm{E}$ ) during 1998 and 1999 . In 1998, fifteen species in five replicates (Table 1) were planted in a randomized complete-block design, in $0.75-\mathrm{m}^{2}$ plots. Plots were planted in research vineyards (Vitis vinifera L.) of 'Chardonnay,' 'White Riesling,' 'Cabernet Sauvignon', and 'Chenin Blanc'. Vine spacing was $1.8 \mathrm{~m}$ between vines and $3.1 \mathrm{~m}$ between rows; vines were drip-irrigated. Forty-five seeds were sown in a prepared seedbed in a grid pattern in each plot. Plots were irrigated with microsprinklers initially to allow for uniform germination, which were removed after 3 weeks. No additional irrigation other than drip-irrigation to vines was applied. The soil was a Warden silt loam (coarse-silty, mixed, mesic Xeric Haplocambid).

For 1999, based on the results during the 1998 season, 10 cover crop selections were replicated four times (Table 2) in a commercial vineyard of 4-year-old, own-rooted Vitis vinifera cv. Merlot trained to a spurpruned, bi-lateral cordon system [Alderridge

Table 1. 1998 rankings of mean percent vegetative cover $(n=5 ; \pm$ SD. $)$ using subjective visual estimate and digital image analysis methods. Scale for rankings: $1=$ lowest cover; $13=$ highest cover. Common names for various selections are listed below scientific names.

\begin{tabular}{|c|c|c|c|c|}
\hline Species & $\begin{array}{l}\text { Visual } \\
\text { estimate }\end{array}$ & Ranking & $\begin{array}{l}\text { Digital image } \\
\text { analysis }\end{array}$ & Ranking \\
\hline Medicago orbicularis \#1 & $51 \pm 5.4$ & 5 & $10.4 \pm 4.5$ & 5 \\
\hline Medicago orbicularis \#2 & $66 \pm 13.4$ & 10 & $6.8 \pm 5.5$ & 2 \\
\hline Medicago orbicularis \#3 & $44 \pm 25.3$ & 4 & $10.5 \pm 8.1$ & 6 \\
\hline Medicago rigidula \#1 & $44 \pm 10.8$ & 4 & $8.8 \pm 5.2$ & 4 \\
\hline Medicago rigidula \#2 & $63 \pm 10.9$ & 9 & $12.0 \pm 4.9$ & 8 \\
\hline Medicago rigidula \#3 & $53 \pm 10.9$ & 6 & $14.4 \pm 4.5$ & 11 \\
\hline Medicago littoralis & $57 \pm 28.6$ & 8 & $11.5 \pm 7.8$ & 7 \\
\hline Medicago scutellata & $75 \pm 9.3$ & 11 & $13.6 \pm 4.5$ & 10 \\
\hline Medicago lupulina & & & & \\
\hline 'George' black medic & $43 \pm 24.6$ & 3 & $12.8 \pm 8.6$ & 9 \\
\hline Medicago lupulina & & & & \\
\hline 'Dr. B' black medic & $44 \pm 12.4$ & 4 & $15.2 \pm 4.3$ & 12 \\
\hline $\begin{array}{l}\text { Trifolium subterraneum } \\
\text { 'Koala' sub-clover }\end{array}$ & $33 \pm 13.5$ & 1 & $5.5 \pm 4.4$ & 1 \\
\hline Trifolium hirtum & & & & \\
\hline $\begin{array}{l}\text { 'Monte Frio' rose clover } \\
\text { Medicago polymorpha }\end{array}$ & $44 \pm 12.9$ & 4 & $8.0 \pm 4.0$ & 3 \\
\hline $\begin{array}{l}\text { 'Carpet' medic } \\
\text { Secale cereale }\end{array}$ & $55 \pm 25.3$ & 7 & $12.0 \pm 9.8$ & 8 \\
\hline Cereal rye & $78 \pm 7.5$ & 12 & $17.6 \pm 5.1$ & 13 \\
\hline $\begin{array}{l}\text { Agropyron cristatum } \\
\text { 'Fairway' crested wheatgrass } \\
\mathrm{CV}(\%)\end{array}$ & $\begin{array}{c}36 \pm 9.6 \\
28.1\end{array}$ & 2 & $\begin{array}{c}8.0 \pm 6.0 \\
52.3\end{array}$ & 3 \\
\hline
\end{tabular}

Vineyards, Alderdale, Wash. (lat. $45^{\circ} \mathrm{N}$; long. $\left.119.8^{\circ} \mathrm{E}\right)$ ]. The soil was a Prosser-Bakeoven complex (Prosser: sandy-loam, coarse-loamy, mixed, superactive, mesic Xeric Haplocambid; Bakeoven: cobbly-loam, loamy-skeletal, mixed, superactive, mesic Lithic Haploxeroll). Seedbeds were prepared by disking between rows. Legumes were pre-inoculated with the appropriate strain of rhizobia inoculum and scarified with sandpaper before planting. Seed was drilled $5 \mathrm{~cm}$ deep (Tye Drill, Duluth, Ga.) in Dec.1998, to take advantage of winter precipitation (51.27 mm between December and March). Plots were $878 \mathrm{~m}^{2}$ (three rows, 1.5 $\mathrm{m} \times 195 \mathrm{~m}$ ) replicated four times in randomized complete blocks. Resident vegetation ("weeds") was used as a control. The vineyard was mown periodically to maintain all cover crops at $8 \mathrm{~cm}$. The mower height was above the tops of the prostrate-growing selections, and did not appear to affect them. The only water added between vine rows was by precipitation
( $9.13 \mathrm{~mm}$ between March and September). No fertilizers or herbicides were applied to cover crop treatments during the experiment.

Image collection and analysis. A $0.25-\mathrm{m}^{2}$ quadrat was placed centrally in the plot (1998) because of small plot size, or randomly (1999) in each plot and visually estimated within the quadrat. Visual estimates were made by only one person to avoid the inherent variance of multiple assessors. Plots were then photographed with a digital camera (Olympus D-500L, Japan) from directly above using a flash to create uniform backlighting (Fig. 1A). Measurements were made on overcast days to minimize shadows. Images were transferred to a computer and percent cover was assessed with a commercial software package (Sigma Scan Pro, 5.0; SPSS, Chicago.). The accuracy of the image analysis software was calibrated against images of green paper shapes of known area $\left(100 \mathrm{~cm}^{2}\right)$ set on top of the soil and photographed under the same conditions as

Table 2. 1999 rankings of mean percent vegetative cover $(n=4 ; \pm$ SD) using visual assessment and digital image analysis methods. Scale for rankings: $1=$ lowest; 13 = highest cover. Common names for various selections are listed below scientific names.

\begin{tabular}{|c|c|c|c|c|}
\hline Species & $\begin{array}{c}\text { Visual } \\
\text { estimate }\end{array}$ & Ranking & $\begin{array}{l}\text { Digital image } \\
\text { analysis }\end{array}$ & Ranking \\
\hline Secale cereale Cereal Rye & $55.0 \pm 23.5$ & 10 & $32.0 \pm 16.6$ & 9 \\
\hline \multicolumn{5}{|l|}{ Agropyron cristatum } \\
\hline 'Fairway' crested wheatgrass & $45.0 \pm 14.7$ & 7 & $28.6 \pm 14.9$ & 8 \\
\hline \multicolumn{5}{|l|}{ Trifolium subterraneum } \\
\hline 'Koala' sub-clover & $12.5 \pm 2.9$ & 3 & $17.2 \pm 2.9$ & 5 \\
\hline \multicolumn{5}{|l|}{ Medicago polymorpha } \\
\hline 'Santiago' burr medic & $48.8 \pm 20.6$ & 8 & $20.0 \pm 9.3$ & 6 \\
\hline \multicolumn{5}{|l|}{ Trifolium hirtum } \\
\hline 'Monte Frio' rose clover & $17.5 \pm 9.6$ & 5 & $10.8 \pm 6.5$ & 3 \\
\hline \multicolumn{5}{|l|}{ Medicago lupulina } \\
\hline 'George' black medic & $10.0 \pm 10.0$ & 2 & $9.3 \pm 5.4$ & 1 \\
\hline Sherman Big Blue Grass & $16.8 \pm 17.4$ & 4 & $16.6 \pm 18.0$ & 4 \\
\hline Fescue Mix (Sheep, Tall, Hard) & $7.5 \pm 5.0$ & 1 & $10.3 \pm 7.3$ & 2 \\
\hline \multicolumn{5}{|l|}{ Lolium perenne, Agropyron cristatum } \\
\hline \& Elytrigia intermedia 'Canada mix' & $42.5 \pm 6.4$ & 6 & $28.2 \pm 6.0$ & 7 \\
\hline Control (resident vegetation) & $51.3 \pm 16.5$ & 9 & $36.6 \pm 8.8$ & 10 \\
\hline $\mathrm{CV}(\%)$ & 41.2 & & 45.7 & \\
\hline
\end{tabular}


described for vegetation to obtain the standard relationship between pixel distances as related to the known area.

Digital images of cover crop plots were: 1) calibrated by defining the quadrat area ( 50 $\mathrm{cm} \times 50 \mathrm{~cm}=0.25 \mathrm{~m}^{2}$ ) in the software using the two-point calibration function (points on opposite edges of the quadrat frame); 2 ) then analyzed with a color threshold that was used in calculating percent of the image area composed of green plant material. A color threshold was set using the software color threshold function (hue: 32-140; saturation: 7-100) to define green plant areas (Fig. 1a). Percent cover was computed (Fig. 1B) from the proportion of defined green pixels as compared to total pixels in the image (Fig. 1C). In 1998, plots were hand-weeded to eliminate all but the cover crop selection and all debris due to weeding and or senescence of tissue was removed before photographing. In 1999, plots were not weeded, so plant tissue from crop and weed senescence was present on the soil surface as this research was part of a larger cover crop selection study. In images with surface litter, a highlighted layer was added to the image during color analysis to differentiate litter and cover crop. This defined the cover crop area and left in the image litter on the surface that was not actively growing. The presence of two main colors (green for cover crop and a brown shade for senescing material) necessitated a transformation of color to grayscale image. The entire image was transformed to grayscale to measure its absolute intensity using an intensity threshold function. A combination of color and intensity thresholds are advantageous because certain areas of a digital photograph can reflect in the green waveband and interfere with calculation of percent cover (Ewing and Horton, 1999). With an intensity histogram, the user sets levels of brightness. Additionally, black, white, and gray or brown colors are often difficult to define in a color threshold. In cases where weeds were present, grayscale images were compared with the original, color digital images to allow the user to "erase" highlighted areas of weed cover. Color and intensity thresholds were combined to identify all areas of the plots covered by vegetation, including litter from weeds and/or the ground cover. The intensity threshold delimited those areas of the image that could not be determined solely from the color threshold. Intensity thresholds varied with each grayscale image. Area due to ground cover was then calculated. Differences in percent cover between visual estimation and digital image

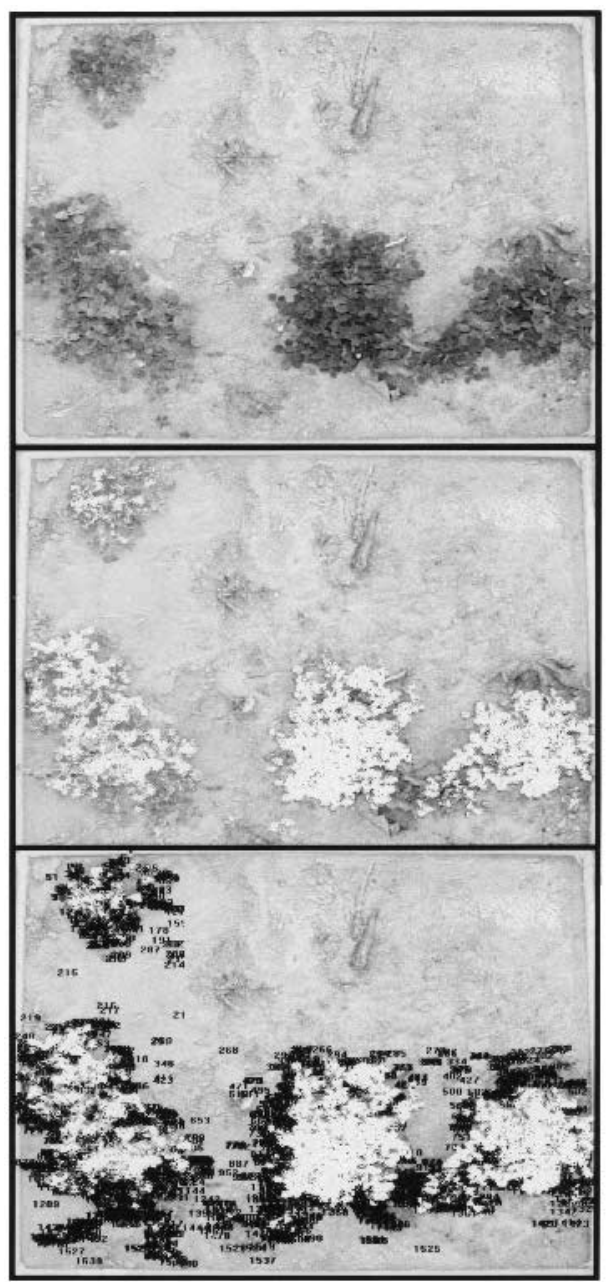

A

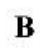

C

Fig. 1. Digital images of plot containing Medicago lupulina cv. Dr. B before image analysis (A); with highlighting layer identifying green areas of the plot (B); and the same image with numbers identifying individual area measurements $(\mathbf{C})$. analysis were calculated and expressed as a ratio to determine the over-or underestimation of percent cover by visual assessment; perfect agreement between the two methods yielded a ratio of 1.0.

Statistical analysis. Analysis of variance using general linear models (GLM) was performed in both years to observe differences between species and between methods. Digital and visual methods were compared by rankings using the Mann-Whitney test $(\alpha=0.05)$; a nonparametric procedure that adjusts for ties in the rankings (Ott, 1993). Regression analyses were used as a parametric procedure to detect differences between the two methods. Coefficients of variation were calculated for all plant selections by taking the original image and analyzing three times. All statistical analyses were performed using Minitab Statistical Software (Release 12.0, Minitab, State College, Pa.).

\section{Results and Discussion}

The digital analysis software estimated the areas of square and irregular paper images to within $1.3 \%$ of their known values, and produced much lower estimates of percentage cover than visual assessments. Visual estimates of the percentage of vegetative cover from the 1998 research plot images ranged from $33 \%$ to $78 \%$ (mean $=52.4 \%$ ) among species, whereas digital analysis of the same images ranged from $5.5 \%$ to $17.6 \%$ vegetative cover (mean $=11.1 \%$; Table 1). In 1999, visual estimates in commercial vineyard plots ranged from $7.5 \%$ to $55 \%$ vegetative cover $($ mean $=30.7 \%)$, while digital analysis of the same images gave $9.3 \%$ to $36.6 \%$ cover $($ mean $=20.1 \%$; Table 2 ). Visual estimates usually overestimated cover, but were positively correlated with digital assessments in both $1998\left(r^{2}=0.30 ; P<0.001\right)$ and 1999 , with improved agreement between the methods $\left(r^{2}=0.68 ; P<0.05\right)$ (Fig. 2). Rankings of percent area due to cover crop suggest that both methods could identify those plots with the highest and lowest percent cover (Tables 1 and 2). Estimated value of mean percent cover was different between methods and in both years $(P \leq 0.001)$. There were no significant differences between the rankings derived by the two assessment methods. The coefficients of variation $(\mathrm{CV})$ were lower for visual assessment than for digital image analysis in 1998 (Tables 1 and 2). Thus, during this year, visual assessment was more reproducible than digital image analysis. These findings were similar to results in a study involving measurement of powdery mildew in cherries (Olmstead et al., 2000), and contrary to our hypothesis. However, in 1999, there were little differences between the $\mathrm{cv}$ for either method, indicating both methods were sufficiently reproducible during this year. This indicates that initially, visual estimation was superior to digital image analysis; however, as the assessor gained experience, the variability among measurements was reduced (Tables 1 and 2).

In 1998 , there were differences $(P \leq 0.001)$ in percent vegetative cover among plant selections, which the two assessment methods gener- 
ally detected but not consistently $(P \leq 0.05)$. It is possible that both assessment methods were inconsistent because of the extremely small amount of cover in all plots ( $5 \%$ to $15 \%$ cover), a consequence of small plot size, low rainfall, and poor stand establishment. In 1999, estimates of percent cover differed among selections $(P \leq 0.001)$ and by method of assessment $(P \leq 0.001)$, although not consistently from selection to selection.

Data from selections that were grown in both years were pooled because of equal variances (F-test, $P=0.288$ ) to determine year-to-year differences and interactions between year and method of assessment. 'Koala' sub-clover, 'Monte Frio' rose clover, 'Fairway' crested wheatgrass, cereal rye, and 'George' black medic differed from each other in both years $(P=0.01)$, but each species performed similarly from year to year $(P=0.22)$. Although it was expected that both assessment methods would be consistent from year to year, visual assessment was not consistent $(P=0.04)$ because of inherent growth variations between plots. It is also possible that the lack of consistency was due to the absence of consistent differences. By 1999, there was better agreement between visual and digital methods $(P<0.001$; Fig 3$)$. These results indicate the potential use of digital technique to evaluate the effect of assessor experience or as a training tool for technicians.

In this study, visual discrimination increased as the size of the stimulus increased, in agreement with the interpretation of the Weber-Fechner Law (Lindow and Webb, 1983). The relative accuracy or objectivity of visual assessment declined as plot cover approached $50 \%$; however, no plot had $>50 \%$ cover so we were unable to examine the entire response predicted by the Weber-Fechner law. In 1998, as percent cover decreased, the discrepancy between visual and digital methods increased (Fig. 2). However, in 1999, at lower percentages of cover, the visual and assessments were closer to those measured by image analysis. As values approached $50 \%$, the visual method was more likely to overestimate cover. Thus, as percent cover values approach $50 \%$, digital image analysis is superior to visual assessments because of heightened accuracy.

Despite the initial repeatability differences in this study, digital image analysis is efficient for field applications because of its accuracy. Although new technologies allow repeated digital capture of canopy cover, the instrumentation may be cost prohibitive. The method described here is affordable for both researchers and growers to analyze canopy cover. Digital image analysis is also useful training multiple assessors for a single project, as well as comparisons of data from different projects and multiple years. Finally, digital image analysis provides a permanent record. To assess percent cover in research, accuracy and precision must exceed the apparent limits of the visual method; one solution is digital image analysis (Gitelson et al., 2002).

Digital image analysis does have some limitations that should be considered. One limitation of digital image analysis is that there must be sufficient contrast between soil and plant to
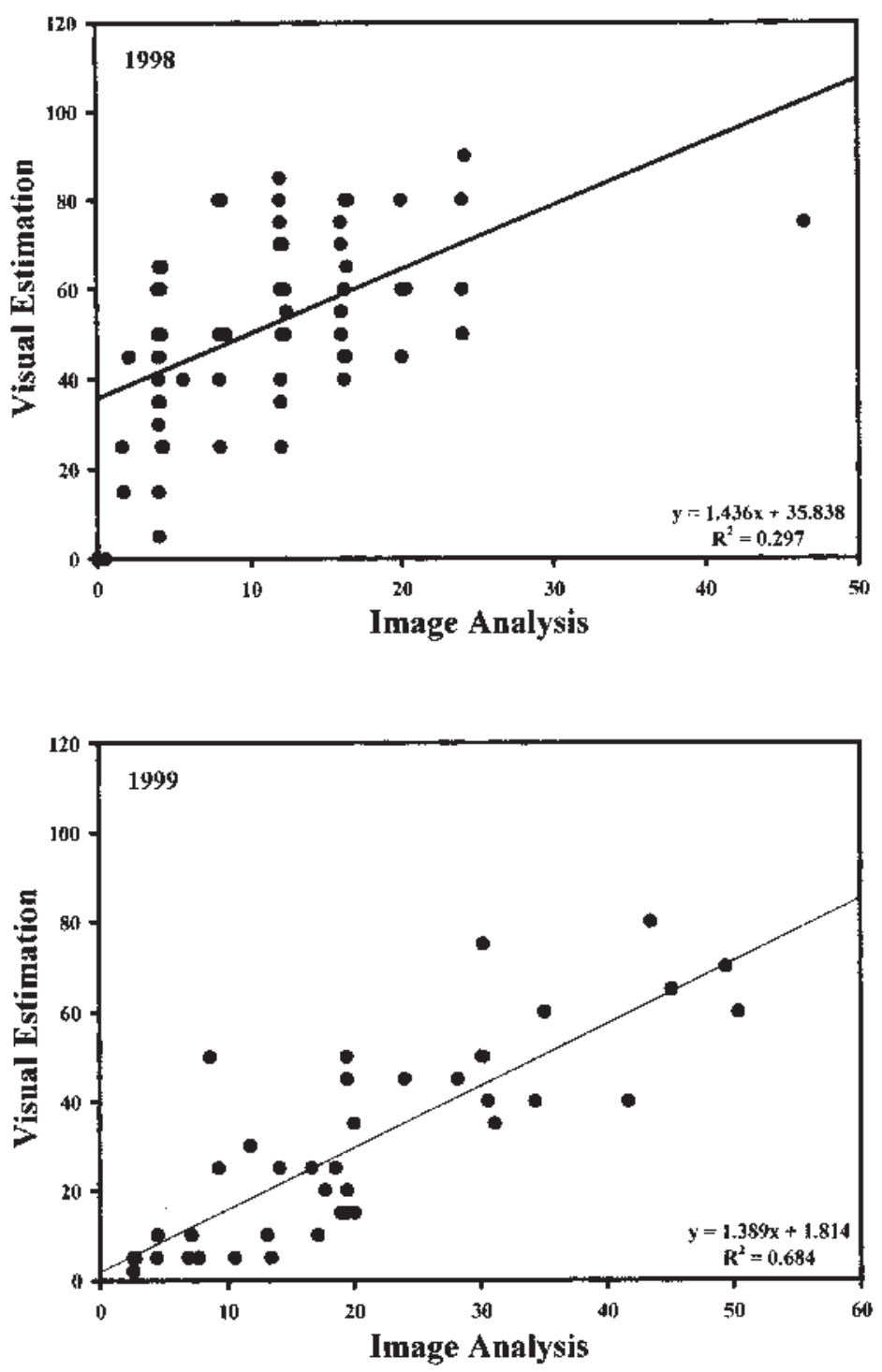

Fig. 2. 1998 and 1999 regression analysis of percent vegetative cover as determined by visual estimation and image analysis.

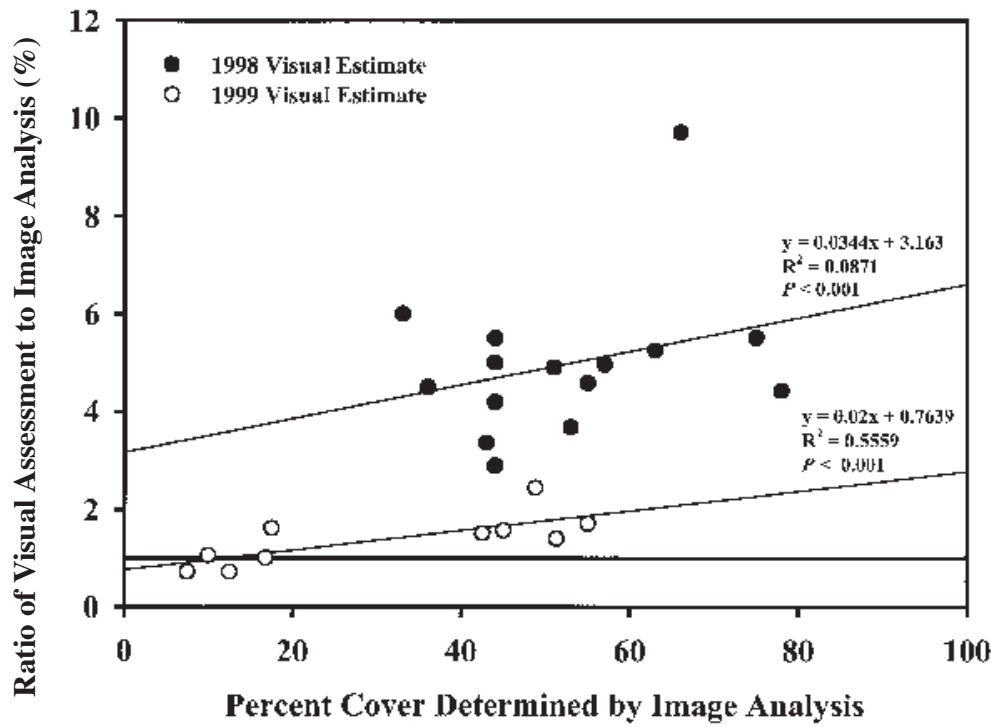

Fig. 3. Comparison of visual assessment expressed as a ratio of percent cover determined by visual assessment to that calculated by digital analysis. The reference at line 1 indicates perfect agreement between the two methods. Fitted lines indicate the general trend. 
produce a usable image. If an image with poor contrast is used, the software cannot distinguish between plant and soil; thus, the estimate of percent cover could be inaccurate. (Furthermore, image analysis software responds only to user-defined commands; if the human eye cannot detect a difference in color or contrast, neither will the digital system.) Photographic techniques such as backlighting, mirrors, and strobe lights can maximize the quality of the digital images. A second potential limitation encountered with digital analysis is derived from collecting overhead images. Zenith-angle images (directly over the top of the plant) do not indicate or adjust for plant height (Molloy and Moran, 1991). A tall cover crop would appear to cover more area because it is closer to the lens than the rest of the plot. In this case, an equation can be applied to correct the error (Molloy and Moran, 1991). In addition, although the original hypothesis that digital image analysis was more reproducible than visual image analysis was rejected, agreement between the two methods improved in 1999. Despite these potential limitations, the benefits of digital image analysis outweigh its current limitations. Measurements are easily accessible for review using digital databases than are those from subjective visual estimates. The computer-assisted image analysis method described in this paper improves upon the accuracy of traditional subjective methods of assessing vegetative cover (e.g., visual assessment.) Digital image analysis was accurate to within $3 \%$ if standardized to images of known area. Additionally, the method reduces the time involved in manually measuring percent vegetative cover and simplifies and reduces the cost of equipment compared to other digital techniques (e.g., video capture, satellite imagery or dedicated green camera).

\section{Literature Cited}

Adams, J.E. and G.F. Arkin. 1977. A light interception method for measuring row crop ground cover. Soil Sci. Soc. Amer. J. 41:789-792.

Bennett, L.T., T.S. Judd, and M.A. Adams. 2000. Close-range vertical photography for measuring cover changes in perennial grasslands. J. Range Mgmt. 53:634-641.

Beverly, R.B. 1996. Video image analysis as a nondestructive measure of plant vigor for precision agriculture. Commun. Soil Sci. Plant Anal. 27:607-614.

Coldwell, A.E., P.R. Loewen, and C.J. Whitfield. 1942. The relation of various types of vegetative cover to soil drift. Agron. J. 34:702-710.

Coren, S. and J.S. Girgus. 1978. Seeing is deceiving: The psychology of visual illusions. Lawrence Erlbaum \& Assoc., Hillsdale, N.J.

Dietz, H. and T. Steinlein. 1996. Determination of plant species cover by means of image analysis. J. Veg. Sci. 7:131-136.

Ewing, R.P. and R. Horton. 1999. Quantitative color image analysis of agronomic images. Agron. J. 91:148-153.

Freebairn, D.M. and G.H. Wockner. 1986. A study of soil erosion of Vertisols of the Eastern Darling Downs, Queensland. I. Effects of surface conditions on soil movement within contour bay catchments. Austral. J. Soil Res. 24:135-158.

Gitelson, A.A., Y.J. Kaufman, R. Stark, and D. Rundquist. 2002. Novel algorithms for remote estimation of vegetation fraction. Remote Sens. of Env. 80:76-87.

Horsfall, J.G. and Barratt, R.W. 1945. An improved grading system for measuring plant diseases. Phytopathology 35:655. (Abstr.)

Lang, N.S., J. Silbernagel, E.M. Perry, R. Smithyman, L. Mills, and R.L. Wample. 2000. Remote image and leaf reflectance analysis to evaluate the impact of environmental stress on grape canopy metabolism. HortTechnology 10: 468-474.

Lindow, S.E. and G.L. Andersen. 1986. Microcomputer measurements of pathogen injury to weeds.
Weed Sci. 34 (Suppl. 1):38-42

Lindow, S.E. and R.R. Webb. 1983. Quantification of foliar plant disease symptoms by microcomputer-digitized video image analysis. Phytopathology 73:520-524.

Molloy, J.M. and C.J. Moran. 1991. Compiling a field manual from overhead photographs for estimating crop residue cover. Soil Use Mgt. 7(4):177-183.

Olmstead, J.W., G.A. Lang, and G.G. Grove. 2000. Assessment of severity of powdery mildew infection of sweet cherry leaves by digital image analysis. HortScience 36:107-111.

Ott, R.L. 1993. An introduction to statistical methods and data analysis. Duxbury Press, Belmont, Calif. p. 279-285

Shelton, D.P., G.E. Meyer, E.C. Dickey, A. Stepanek, and K.T. Fairbanks. 1988. Electronic image analysis to determine crop residue cover. Proc. $2^{\text {nd }}$ Intl. Conf. on Computers in Agr. Ext. Programs. Fla. Coop. Ext. Serv., IFAS, Univ. of Fla.

Sherwood, R.T., C.C. Berg, M.R. Hoover, and K.E. Zeiders. 1983. Illusions in visual assessment of stagonospora leaf spot of Orchardgrass. Phytopathology 73:173-177.

Silbernagel, J. and M. Moeur. 2001. Modeling canopy openness and understory gap patterns based on image analysis and mapped tree data. Forest Ecol. Mgt. 149:217-233.

Stocking, M.A. 1988. Assessing vegetative cover and management effects, p. 163-185. In: R. Lal (ed.). Soil erosion research methods. Soil and Water Conservation Soc., Ankeny, Iowa.

Stredansky, J. 1999. Reduction of wind erosion intensity by vegetation cover. Ekologia 18: 96-99.

Woebbecke, D.M., G.E. Meyer, K. Von Barge, and D.A. Mortensen. 1995. Shape features for identifying young weeds using image analysis. Trans. ASAE 38:271-281.

Yonekawa, S., N. Sakai, and O. Kitani. 1996. Identification of idealized leaf types using simple dimensionless shape factors by image analysis. Trans. ASAE 39:1525-1533. 